\title{
La ironía del Quijote: lecciones de lectura inversa
}

\author{
Pedro GUERRERO RUIZ \\ Universidad de Murcia \\ Departamento de Didáctica de la Lengua y la Literatura \\ guerrero@um.es \\ María Teresa CARO VALVERDE \\ Universidad de Murcia \\ Departamento de Didáctica de la Lengua y la Literatura \\ maytecar@um.es \\ María GONZÁLEZ GARCÍA \\ Universidad de Murcia \\ Departamento de Didáctica de la Lengua y la Literatura \\ mgonzalezgarcia@um.es
}

Recibido: noviembre 2010

Aceptado: marzo 2011

\section{RESUMEN}

Este artículo plantea el poder educativo de la imaginación para proponer símbolos que comunican autor y lector. Por ella, los clásicos de la literatura siguen vivos en épocas posteriores a las de su escritura, gracias a la capacidad de los lectores para intimar con el texto y renovarlo creativamente con otras perspectivas e hipertextos nuevos que desencadenan una semiosis infinita.

El Quijote es un libro idóneo para estimular lecturas creativas debido a su condición hospitalaria hacia cualquier cultura y generación. La ironía es la retórica nodal del clásico cervantino y provoca "lecciones" de lectura inversa, interpretaciones cuerdas para ejemplos locos. Leyéndolo, se aprende a usar la fantasía no para la creencia en los significados sino para el sentido crítico hacia el mundo de referencia.

Palabras clave: imaginación, clásico, hipertexto, ironía.

\section{L'ironie du Quichotte : des leçons de lecture inverse}

\section{RÉSUMÉ}

Cet article présente le pouvoir éducatif de l'imagination pour proposer des symboles qui font communiquer l'auteur et le lecteur. Dû à cela les classiques de la littérature continuent à être présents dans des époques postérieures à celles de leur publication, c'est la capacité des lecteurs, pour intimer avec le texte et le renouveler créativement avec d'autres perspectives et de nouveaux hypertextes, celle qui développe une sémiose infinie.

Le Quichotte est un livre idéal pour stimuler des lectures créatives dû à sa condition hospitalière envers toute culture et toute génération L'ironie est la rhétorique nodale du classique cervantesque et provoque des "leçons" de lecture inverse, des interprétations 
raisonnables pour des exemples fous. En le lisant, on apprend à utiliser la fantaisie, non pour croire à des signifiés, mais pour créer un sens critique envers le monde de référence.

Mots-clés : Imagination, classique, hypertexte, ironie.

\title{
Don Quixote's Irony: Reverse Reading lessons
}

\begin{abstract}
This article raises the educational power of imagination in order to propose symbols which communicate author and reader. Thanks to it, classics of Literature keep alive after their writing days, thanks to the readers' capability to get friendly with the text and renew it creatively with other perspectives and new hypertexts which break out an infinite semiosis.

Don Quixote is an ideal book to stimulate creative readings due to its hospitable condition towards any culture or generation. Irony is the nuclear rhetoric of the Cervantes' classic and it provokes 'lessons' of opposite reading, sane interpretations for crazy examples. When reading it, you learn to use fantasy not for the belief in the meanings but for the critic sense towards the reference world.
\end{abstract}

Keywords: imagination, classic, hypertext, irony.

SUMARIO: 1. La imagen viva de los clásicos: su modernidad. 2. Las travesías del clásico cervantino: el viaje loco a la cordura. 3. Lectura espejo: lectura libre y solidaria. Referencias bibliográficas.

\section{LA IMAGEN VIVA DE LOS CLÁSICOS: SU MODERNIDAD}

La imaginación es la facultad de abstraer la vida de modo personal con imágenes que se construyen en el pensamiento. Aprovecha ecológicamente lo antiguo y se vincula creativamente a lo nuevo, ya que se estimula con todo lo otro en su diversidad y riqueza; de ahí que una de sus acciones iniciales sea la contemplación estética, que admira las obras en su belleza singular sin objetualizarlas.

Por la imaginación cobran coherencia vital las dimensiones del humanismo y del hipertexto, pues, gracias a ella, se establecen vínculos entre disciplinas y culturas. "La imaginación, como base de toda actividad creadora, se manifiesta por igual en todos los aspectos de la vida cultural posibilitando la creación artística, científica y técnica", afirma Vigotsky (1982:10-12). Todo lo que nos rodea y ha sido creado por la mano del hombre es producto cultural de la imaginación.

La literatura tiene la suerte de disfrutar de la fuerza imaginativa que genera cultura viva. Luego el fomento de esta capacidad humana en el mundo de la educación tiene una importancia capital para desarrollar la madurez creadora de niños $\mathrm{y}$ adultos. En este sentido, Todorov discierne que "como la filosofía, como las ciencias humanas, la literatura es pensamiento y conocimiento del mundo psicológico y social en el que vivimos" (Todorov, 2009: 84). En efecto, la literatura aspira a entender la experiencia humana. Pensemos en los versos "Camarada, esto no es un libro. / Quien lo toca, toca a un hombre" que poetizó Walt Whitman en Hojas de hierba. Nos recuerdan que un libro sigue su cauce comunicativo si el motivo que despierta la imaginación del lector o del escritor es cercano a sus vidas. Mientras que 
lo distante permite, como mucho, imitación, no obstante lo cercano genera, de modo natural, interacción. Según argumenta Antonio Mendoza (2006), así se trabaja la educación literaria como la vertiente más significativa de la Didáctica de la Literatura, pues se centra en la interacción del mundo del lector con el de la obra literaria para alimentarse, de modo holístico, de las prácticas lectoescritoras que generan interpretación y creación.

La lección literaria no impone tesis, sino que propone hipótesis que el lector interpreta simbólicamente, conmovido por el sentido que en sí mismo produce el texto. El simbolismo transforma la experiencia en idea y la idea en imagen. Así, la imaginación dota de actividad comunicativa a las imágenes simbólicas porque pretende hacer "vivir" el lenguaje humano.

Por ella, el análisis (la inducción) y el entendimiento (la deducción) de la experiencia comunicativa se proyectan hacia la dinámica de la creación (la abducción) (Herrero, 1998). La imaginación "abduce" puesto que "imaginar" difiere de "ilustrar" en la medida que en su ámbito la iconicidad es ilusión del discurso y no su comprobación posterior; luego se proyecta en perspectiva subjuntiva hacia el futuro perfectible, no testifica el manifiesto indicativo del pasado irrevocable.

Por ella, entonces, existen puentes de simpatía plurales y multiformes entre literatura y vida. Es más: la "vida" de la literatura está en manos de aquellos lectores capaces de intimar con el texto y renovarlo en sus imaginarios con otras perspectivas nuevas conformes a sus experiencias particulares.

Tal es la teoría literaria de la imaginación que sostuvo Azorín en su ensayo "El arte de leer" de su libro Estética y política literarias (Azorín, 1963: 1160-1164) a propósito de su reclamo de los clásicos para la modernidad. En defensa de ellos, se adelantó a las actuales posiciones educativas sobre la necesidad de cultivar la creatividad en las aulas cuando atribuyó a la imaginación una capacidad investigadora de alcance interdisciplinar:

¿Cómo despertar la imaginación? Si hay algo en la vida de subido valor, es la imaginación. La imaginación es la prenda más exquisita con que cuentan los humanos. La imaginación propulsa el progreso, crea las artes y pone amenidad en el trato social. Hombre sin imaginación es hombre inerte. Desde la niñez ha de ir desenvolviéndose tan precioso don. Las lecturas novelescas son las que incrementan la imaginación. En un niño inteligente, pronto de lo novelesco literario se pasará a lo novelesco real, científico. El mundo es una pura novela. Tiene tanto interés la Naturaleza -campos, mares, cielo- como la más apasionante novela. Lo importante es ver en la Naturaleza, ver y sentir, el interés que nos cautiva en la novela. Un niño despierto, vivo, que vea interés en la novela, que lea novelas, que se interese en la lectura del Quijote o de Eugenio Grandet o de El amigo Manso, pronto se interesará en la novela del campo, del cielo y del mar. No pongamos límites a las lecturas de los niños. Las únicas restricciones lícitas son aquellas que marcan la separación entre la materia áurea y la materia vil. No es lo mismo una novela de Cervantes, de Balzac o de Galdós que una novela de un autor ínfimo. Demos de comer intelectualmente a los niños; démosles de comer de todo. (Azorín, 1963: 1163) 
Décadas después incidiría en ello Gianni Rodari al afirmar en su Gramática de la fantasía: "la función creadora de la imaginación pertenece al hombre común, al científico, al técnico; es esencial tanto para los descubrimientos científicos como para el surgimiento de la obra de arte; es, en definitiva, condición necesaria de la vida cotidiana" (Rodari, 1991: 155).

En efecto, se necesitan más iniciativas como la de Rodari para cambiar el triste panorama de los clásicos maltratados en las escuelas. Se les ha vampirizado hasta dejarlos como idílicas momias blancas y occidentales de una tradición cultural supuestamente uniforme y estable que pone murallas de distinción infranqueable frente al caos de las literaturas emergentes y marginales. Al respecto, Pozuelo Yvancos y Aradra Sánchez, al estudiar la teoría del Canon de lecturas escolares, advierten que el sector conservador del profesorado, por el hecho de imponer las lecturas y obligar a memorizar las interpretaciones sobre las mismas, provocan en sus alumnos la reacción contraria a la que pretenden (fomentar la lectura de estos libros). Además, inciden en que el canon occidental ha sido dispuesto de modo forzado:

\footnotetext{
"No es discutible sólo esa universalización en el cronotopo ideológico y muy controvertido que conocemos como Occidente, sino el principio de unidad que se supone a esa tradición situando a Homero junto a Virgilio y Shakespeare, heredero de ambos, y a Cervantes en la misma estirpe de clásicos en una continuidad sin solución o fisuras. Es una evidencia que ni Shakespeare ni Cervantes fueron admitidos sin resistencias notables en tal canon, ni sus obras arrancaron de un lugar homogéneo para con los valores supuestos a la tradición clasicista; antes al contrario actuaron y actúan como potencialidades fuertemente subversivas para con el orden literario establecido en su época, y conservan, como los debates continuos críticos están revelando, iguales potencialidades subversivas." (Pozuelo Yvancos y Aradra Sánchez, 2000: 67)
}

Hay que cultivar los clásicos como alimento de la imaginación inherente a una actividad lectora que reconoce la innovación desde una trayectoria genealógica. Retomamos aquí las teorías krausistas de la Institución Libre de Enseñanza que proponían la escritura artística a partir del reciclaje de la tradición y de su proyección innovadora (Fox, 1997: 47-49). El porvenir de la escritura, hoy denominado "hipertextualidad", no es cuestión de influencias entre autores, sino de reescrituras que conectan intertextos. Retorna así lo moderno de lo clásico, la fuerza superviviente de la tradición ahora recontextualizada desde su posterioridad de mano del lector que se ve atraído por su genuina originalidad y su prestancia al cambio.

Azorín nos trae a la memoria la sabia frase cervantina: "leo de todo". Esta pasión omnívora corresponde en nuestros días a aquellos lectores en los que se despliega el ánimo de indagación interdisciplinar, facilitado por la inmensa accesibilidad de fuentes que proporciona la revolución tecnológica del siglo XXI (Talens, 1994). Por tanto, hoy se hace necesario cuestionar el control institucional de la lectura y sus metodologías asépticas, porque la imagen viva de los clásicos -su modernidad literaria- deconstruye la imposición canónica de isomorfismo empeñada en paralizar 
el pasado con patronajes que someten historia y géneros literarios a procesos de regulación aséptica. La vida de los clásicos construye, en cambio, actos creativos, investigadores, donde conocimiento y comunicación miran hacia el futuro (Guerrero Ruiz, 2006).

Una obra se vuelve clásica porque el tiempo le va dando razón de ser viva en la posteridad. Los clásicos tienen un encanto probado a través de sus lecturas diacrónicas: ser textos sin clausura de sentido. Ello acontece porque albergan imaginarios liberados del asimilacionismo canónico y crecidos en lecturas creativas que los transforman según el gusto y el genio de cada receptor. El culto a la identidad y a la monología con que los clásicos son mitificados por la academia realmente poco tiene que con su pujanza literaria, que se alimenta del cruce de culturas y de disciplinas $\mathrm{y}$, por su riqueza sublime, inabarcable, despiertan la pasión del conocimiento, la indagación. Los clásicos regalan, pues, sabias lecciones de lectura inversa: no son los lectores ni las épocas los que interrogan a los clásicos; antes bien, como avisa Steiner (1998: 32), "El clásico nos interroga cada vez que lo abordamos"

Así pues, desde un enfoque semiótico, el espacio literario se describe como incesante travesía de textos, acorde con la dinámica de la imaginación lectora que no solo asimila la literatura, sino que la reescribe a su manera, de modo curiosamente muy cercano a lo que el mismo Cervantes elaboró con el uso de la parodia: una escritura desatada, que entretiene, que incorpora otras voces y hace, como de él dijo Ortega y Gasset (1987: 163), "una metafísica del mundo como imaginación". La imaginación procura la semiosis infinita de la literatura, que vive del diálogo entre la obra y sus nuevos usos en los contextos socializados de sus lectores futuros. Son los lectores los que, de modo ininterrumpido, producen y transforman los sentidos de la obra a partir de su entramado de inscripción.

La facultad de comunicarse en red reclama un diseño democrático de la educación literaria afianzado en el diálogo como estrategia básica del aprendizaje significativo, para que los docentes motivemos a los discentes a expresarse, a sentirse integrados como personas con voz en el mundo escolar cuando relacionan su cultura heredada con su vida cotidiana.

En el ámbito educativo, la semiosis de la imaginación literaria demanda reciprocidad entre escuela y vida, entre escritura y lectura y entre método y actitud para conferir a la creatividad interdisciplinar e intercultural el protagonismo que merece. Ello está en consonancia con el actual diseño democrático de la competencia comunicativa, que se basa en el diálogo como habilidad básica para promocionar el aprendizaje significativo para toda la vida, la construcción del conocimiento compartido, y el desarrollo del temperamento crítico a partir de la producción de discursos personales.

En este sentido, es clave la teoría semiótica de la "abducción", formulada por Peirce como "creatividad racional" (Peirce, 1980: 210) La abducción alude al movimiento muscular que se produce cuando se quiere atrapar algo externo, rompiendo la armonía ordinaria del cuerpo. Peirce aplica este saber biológico al saber lógico para desbaratar la tradición judicial aristotélica de la "apagogé" o reducción de cualquier silogismo a la forma canónica, pues plantea la abducción como un rapto 
capaz de invertir el silogismo ordinario cuando desencadena los procesos inferenciales hipotéticos en casos problemáticos. Para estos casos, las leyes o hipótesis viejas resultan absurdas, y la abducción resulta así una creación, pues ofrece una ley nueva o una nueva relación entre leyes anómalas y casos.

El ejemplo de un acróstico puede servir para entender mejor el procedimiento abductivo: consiste en reconocer la otra figura escondida en la dada, de forma que así la nueva figura se ve "antes" que la vieja, es raptada, abducida en ésta. Esta doble vinculación (el desenmascaramiento de algo en algo, la atención y la interpretación dirigidas hacia lo nuevo atrapado) es un acto de agudeza ingeniosa, un humor afectivo que precede al lenguaje simbólico y lo genera. La abducción nos hace comprender que el saber creativo no se educa desde la topología sino como tropología, dado que la imaginación es capaz de trasponer lo simbólico con hendiduras y desplazamientos que lo entregan a un proceso de metamorfosis desde el momento en que entra en la dinámica real del intercambio comunicativo: escuchar, hablar, conversar, leer, escribir y mediar son sus impulsos verbales.

La promoción de experiencias hipertextuales con los clásicos en las aulas según el circuito comunicativo de la abducción pone en marcha el "intertexto lector" (Mendoza, 2001), es decir, la capacidad de generar interpretaciones de modo significativo y crítico, donde la lectura genera sentidos correlativos de ánimo creativo desde usos humanos y plurisignificativos de la cultura. Por vía de la abducción, de modo natural, la lectura desenmascara el otro sentido del texto desde el momento en que se siente inspirada a ver algo más que la intención del autor, una cita personal con el mundo del intérprete, un rapto que genera ideas diferentes y nuevas expresiones en la imaginación lectora.

Este encanto del texto que ha tocado al lector como un problema o una promesa abre su apetito de investigar y de prefigurar hipótesis. Así se produce el paso motivado de la lectura significativa a la escritura creativa y la revitalización del clásico en contextos modernos.

\section{LAS TRAVESÍAS DEL CLÁSICO CERVANTINO: EL VIAJE LOCO A LA CORDURA}

El Quijote es un libro idóneo para estimular lecturas abductivas debido a la condición irónica y hospitalaria que Cervantes quiso para él. Así lo expresaba en el prólogo de la novela su autor: "procurad también que, leyendo vuestra historia, el melancólico se mueva a risa, el risueño la acreciente, el simple no se enfade, el discreto se admire de la invención, el grave no la desprecie, ni el prudente deje de alabarla" (Cervantes, 2001: 18). Entre los clásicos hispánicos y mundiales, El Quijote ha sido durante cuatro siglos la novela que más chorros de tinta ha derramado en su fabulosa herencia. Sus hipertextos artísticos y culturales son legión y la imagen quijotesca navega por el inconsciente colectivo como un mito cotidiano de la utopía que acompaña al fracaso y al progreso social como su otro. 
La novela está tejida con guiños de complicidad a edades y países, siglos y culturas, de procedencias muy diversas. No en vano se le conoce como la Biblia de la solidaridad. Pocos libros como éste podrían ofrecer a las expectativas educativas actuales reflexiones valiosas para recuperar a los lectores del terrible maleficio consumista que nos ha traído la invasión tecnológica del siglo XXI, pues por el consumismo mercantilista entra en crisis la capacidad dialogante de los receptores de mensajes, y se atrofia su mente conectiva, responsable y creativa, que es el fundamento último de las Humanidades.

La ironía es la retórica nodal del Quijote y provoca "lecciones" de lectura inversa, interpretaciones cuerdas para ejemplos locos. Su literatura incita, pues, a leer desenmascarando, a usar el escorzo lector que atrapa intertextos en el disco duro de su mente para captar la verdad oculta del texto. Este clásico nacido deliciosamente para la perspectiva y la complicidad sacude la lectura especular del intertexto lector para que la comprensión se vuelva escrutinio de lo otro en lo propio y reformulación del significado autorial en el sentido democrático de cada lectura.

El educador aprende del impulso literario cervantino en la captación y expresión de la ironía que prepara la capacidad de comprensión y de expresión de mensajes ricos en perspectivas de forma y significado, siempre en atención a los contextos comunicativos de aparición y de recepción. Por tanto, se juegan dos tipos de ironía: la ironía de la forma (ser otro), es decir, el destino infinito de la literatura (creatividad hipertextual); y la ironía del significado (el sí es no), es decir, la riqueza polisémica de la literatura. Y sus temáticas quijotescas son la locura (confusión), la hipocresía (encubrimiento) y el destino (mundo al revés).

El clásico cervantino nos enseña con sentido del humor que por la lógica imaginaria del sentido de la enunciación se libera la retórica plural de la lectura que abre los nudos del texto a las redes de su correspondencia hipertextual, donde adquiere proporciones infinitas. Su lección chistosa avisa sobre el giro contextual de la creatividad que -en tanto que criterio didáctico- ofrece a cada lector la oportunidad de desarrollar en el ámbito educativo su mundo lógico y afectivo.

Las travesías quijotescas no nos llevan por caminos únicos, sino que transitan hacia las encrucijadas y se demoran en los paréntesis y los incisos: son sus huellas las historias episódicas, los momentos culminantes entrecortados, y las tesis disuadidas entre la realidad fútil y la locura necesaria. No sirve mirar hacia atrás, porque el trayecto es laberíntico y cuestionable, se resiste al veredicto. Su retórica literaria, jocosamente irónica, es fuente de la novela moderna, no tanto por su polifonía como por el hecho textual de que es una obra que no quita los andamios con que ha sido edificada.

Frente al texto reglado con visión panóptica que borra toda huella del dispositivo del que ha surgido y transforma la complejidad de la realidad en el pie de una letra que asegura el orden del mundo y la lectura aquiescente, Cervantes sube a lomos del texto subversivo que entrega la visión ambulante de un mundo al revés, sin más orden que la conciencia del viaje loco hacia la cordura, el viaje de las hipótesis hacia un sentido no fijado de antemano, sino creado al paso de acontecimientos variables y de la imaginación convivente del lector amable. En el Quijote no hay tópicos firmes. 
Todos están ironizados. Hay aventura paródica que escamotea la moralina estatuaria del género, "camino al andar".

En las aulas españolas de Educación Secundaria se suele hablar despectivamente de la lectura del Quijote, ya sea aquel "plomazo" caído a las manos por obligación, o el "tomaco" tan nombrado en sus tópicos como poco leído por capítulos, a lo sumo los antológicos. Ello es indicio de la inadecuada metodología académica con que se muestra el libro a los alumnos. Por desgracia, se le presenta con serios argumentos que difieren sobremanera de las intenciones cervantinas manifestadas en el prólogo de la novela: "Procurad también que, leyendo vuestra historia, el melancólico se mueva a risa, el risueño la acreciente, el simple no se enfade, el discreto se admire de la invención, el grave no la desprecie, ni el prudente deje de alabarla" (Cervantes, 2001: 18).

Necesariamente, este libro pide una lectura lúdica. Aquellas monografías que así lo han defendido (Torrente Ballester, 1975; Caro Valverde, 2009) también anuncian una lectura abductiva del clásico donde conjugar la vida particular de los jóvenes con el acto de leer el Quijote y de escribir creativamente a su amparo. Cuando la vida viene enhebrada por una sonrisa, hasta los zoquetes que sufren el mal de escuela se sienten motivados a leerla en libertad. Pozuelo nos trae a la memoria el ensayo de Pennac Como una novela cuando invita a leer el Quijote en estos términos:

Tómese el lector su tiempo, no le tenga miedo al Quijote, ni siquiera tiene que leerlo de un tirón y todo a la vez. Puede comenzar viajando por sus capítulos, familiarizándose con su lenguaje, incluso cambiando el orden de lectura. Puede dejarlo si le cansa y volver en otro momento. Reirá, seguro, con el episodio de los batanes o con Maritornes en la venta, llorará con el regreso desde Barcelona hacia su lugar o aldea. Créame el lector que si le concede tiempo y sosiego no habrá cosa que más le guste. (Pozuelo, 2005: 5).

La lectura del Quijote no es fácil pero sí amena, bromista, acepta el desafío de seguir los vericuetos irónicos de la parodia para que nos demos cuenta de que la estructura de la narración dentro de la narración ironiza la interpretación del texto y convierte la ficción en un acto de especulación reflexiva. Como bien anotó Julio Cejador: "Apenas hay frase en el Quijote que no tenga doble sentido y segunda intención, cuando no la tiene tercera, siendo toda la novela una burla irónica" (Cejador, 1905: 285). Con el doble sentido del chiste, Cervantes puso en los pasos de un loco un retrato realista de su mundo argumentado con razones científicas y verosímiles que muestran las huellas de la cordura humanista de su autor.

\section{LECTURA ESPEJO: LECTURA LIBRE Y SOLIDARIA}

El Quijote es un libro especular, ya que obliga a pensar al lector que está ante un "libro". Ello se produce por medio de la estrategia metacognitiva de su retórica de la ironía en pasajes tales como la invención de un autor diferente a Cervantes, la interrupción de la narración en el momento álgido de una disputa entre personajes, o 
la conciencia de que el protagonista tiene fama de papel, pues un tal Avellaneda ha inventado su vida posterior en novela.

Cervantes inauguró un nuevo tipo de escritura literaria que no deja que el lector solace su imaginación en los dulzores de la fantasía creída, sino que le impele hacia la incomodidad de seguir imaginando desde la intemperie crítica de la perspectiva inversa. La estela de grandes escritores que siguieron su ejemplo revela la enorme influencia que el Quijote ha ejercido en la poetología de la posteridad literaria.

Recordemos Les faux-monnayeurs de Gide, novela que se cuenta a sí misma como un juego de espejos paralelos que desconcierta al mezclar vida e ilusión en una "mise en abîme", obra en la obra hasta el infinito; o bien ciertos cuentos de Borges, en especial, "Pierre Menard, autor del Quijote"; y sobre todo los ensayos de Schlegel sobre la ironía romántica nacida de la sensación artística de la vida como paradoja donde conviven lo ideal y lo real en lucha perpetua, pero no para hundirse en la tragedia sino para elevar el espíritu por encima de ello gracias a la risa que pone al hombre más allá de las contradicciones en simpatía con los enigmas (Close, 2005: 267). El Quijote despierta la ironía que funciona en la abducción, pues trabaja el chiste del doble sentido, donde en lo uno cabe lo otro, y es el lector avezado quien debe desenmascararlo. Todo depende del prisma desde el que se mira, de la subjetividad de la experiencia.

La "mentalidad prismática" de Cervantes y su adhesión al principio de "doble verdad" fue la lección que Ortega y Gasset, Azorín y Américo Castro mostraron a la cultura hispánica para restablecer el vínculo con los románticos alemanes. Estudiosos como Spitzer, Hafzfeld o Riley profundizaron en tal consideración del romanticismo sublime del Quijote, de su vastedad interpretativa, ya que la multiplicidad de la ironía cervantina es capaz de abarcarlo todo y disolverlo todo. En su Teoría de la novela en Cervantes Riley aprecia la coexistencia de dos mundos en el planteamiento de la verosimilitud de la ficción cervantina: el ideal y el posible, de donde emerge la incertidumbre cervantina como un principio metodológico de conocimiento en perspectiva, tan irónico como científico:

La mayor crítica que Cervantes hace de los autores de libros de caballerías es acusarles de no ser enteramente conscientes de lo que están realizando en sus propias ficciones. Sus mismas novelas están también llenas de incertidumbres, pero, a diferencia de los otros autores, él se muestra mucho más consciente de esas incertidumbres. (Riley, 1981: 432)

En esta línea interpretativa destaca el ensayo de Carlos Fuentes titulado "Elogio de la incertidumbre" (Fuentes, 2005: 156-171), donde postula que, al igual que la autoría y la onomástica quijotesca son susceptibles de muchas explicaciones, también lo es nuestra realidad mutable y compleja:

Don Quijote es un lector de todos los libros que se convierten en un libro leído por todos los lectores. Ya desde la primera parte, Quijote habla de "el sabio que habrá de escribir esta historia". Ya vimos la pluralidad autoral que nos ofrece el libro de don Quijote. Pero hay un momento en el cual el problema ya no es quién escribió el libro sino 
quién lo leyó, lo lee y lo leerá. Ese momento ocurre cuando don Quijote, el lector afiebrado, se sabe leído e impreso. Don Quijote deja atrás sus propias lecturas y es perseguido por su propio libro. Al cabo, el libro lo alcanza y se convierte en él. El personaje don Quijote se transforma en el libro Don Quijote.

$\mathrm{Si}$ en la primera parte don Quijote puede preguntar: ¿quién me escribe?, en la segunda puede exclamar: ¡soy escrito!

Unidos para siempre el personaje y su libro, de este ayuntamiento nace el lector del libro. El lector del Quijote aparece necesariamente cuando se rompen las fronteras narrativas del libro y desaparecen las cercas que separaban al narrador de lo narrado y al lector de lo leído.

Así como don Quijote no escribe nuevos libros de caballerías sino que los vive, para seguirlos leyendo debe actuarlos pero para seguir viviendo va a necesitar del lector de su propia épica cómica. (Fuentes, 2005: 158-159)

El lector queda perplejo ante la doble verdad del Quijote, especialmente cuando advierte el género multiplicado, el autor escamoteado y los antropónimos burlones que generan incertidumbre desde el perspectivismo y la reversibilidad. Este libro que se mira en el espejo de saberse leído también enseña al lector a verse en el espejo de la actualidad incierta y del conocimiento democrático de la verdad.

Precisamente por su capacidad de asociar lo dispar, el espectro imaginario del Quijote es perfecto para educar en la interdisciplinariedad que, con ánimo democrático, desmantela la imposición de una sola cultura mediante el reconocimiento y la interconexión de la diversidad para la convivencia. Su entramado no se basa en la oposición sino en la integración comunicativa de personas de orígenes plurales. La autenticidad existencial de este libro procede, pues, de la empatía hacia el otro, de su especularidad no narcisista, sino sociable.

La intensa competencia comunicativa de este libro permite postular la tesis de que fue concebido voluntariamente por su autor, no para un lector modelo en concreto, sino para cualquier tipo de lector (Rodríguez, 2003: 21), porque no ha sido escrito a la medida de su autor sino hacia la magnitud de sus lectores libres. Quienes lo leen se miran en él: Paul Verlaine en su bohemia de altas fantasías, León Felipe en el honor de su cabalgadura, Rubén Darío en su hidalguía triste (García Montero, 2005:30-33; 115). El Quijote conmueve hacia la solidaridad. Después de cuatro siglos, así lo sigue viendo Harold Bloom: "el hidalgo español es un hombre que se preocupa por sí mismo, por Sancho y por quienes necesitan ayuda"(Bloom, 2005: 96).

Existe un Quijote para cada lector. $\mathrm{Su}$ inspiración democrática, capaz de recontextualizarse con cada imaginario y época, lo ha convertido en un hipertexto de proporciones inmensas, hasta el punto de que hoy en día se le utiliza como herramienta de convivencia social (González García, 2009). Por ello, es un texto óptimo para educar en los valores y en la retórica que dan entidad a la literatura mestiza de géneros, temas y culturas, y capaz de deconstruir, por efecto, los argumentos de autoridad en que se basan las culturas dominantes y sus colonialismos de globalización unilateral. Recordemos las palabras de Lázaro Carreter $(1985,119)$ "Cervantes compone la primera novela polifónica del mundo. La heterología, la multitud de estilos que en ella conviven, constituye la señal de su modernidad." 
El lector de novelas aprende a ir perfilando sus hipótesis interpretativas sobre el texto conforme se despliega sus espacios semánticos en complejidad. En el caso del Quijote, Cervantes no se conformó con trabajar la simplicidad lógica de la contraposición y de la causa-efecto; tampoco con el análisis contrastivo de un dilema en busca de alternativas; pues ejercitó su pluma en esfuerzos de estilo más complejos, reunidos en el juego de la parodia.

Cuando un texto parodia a otro, surge la experiencia abductiva, ya que un argumento muestra cómo un concepto presupone otro con una intención y en un contexto diferente que engloba al anterior. Por tanto, su recreación imaginativa, integradora de lo otro en lo propio, es tan compleja e inteligente como cómica y natural en lo tocante al desenvolvimiento del hipertexto, que vive del diálogo de perspectivas, no de posiciones enfrentadas, pues reutiliza todos los fundamentos y las posiciones que presumían ser definitivas. Y si esta inteligencia paródica se mueve con pulso humanista, sucede que constituye una estrategia literaria para la solidaridad, diálogo cooperativo y plural en obras de beneficio social.

La educación a través del diálogo solidario, más que un espacio para la transmisión del conocimiento, es un espacio para el reconocimiento del sentido de la información, una forma de construir el saber desde el entendimiento y comprensión con los otros. Cuando los textos dialogan con la realidad de los lectores, surge la conciencia crítica, es decir, la facultad de repensar la propia identidad en perspectiva y el afán de transformar la sociedad.

A fin de cuentas existen dos pedagogías de la lectura: de un lado, la controladora, de tendencia correctiva para lograr la universalidad, la verdad objetualizada en el mejor de los casos por vía del consenso con la intención de homogeneizar y estabilizar el sentido. Su corrección se basa en el control de los límites entre lo decible y lo indecible, entre la razón y delirio. De otro lado, la experimental, de tendencia jugadora para crear las condiciones de la pluralidad de sentido, la verdad liberadora. Tal es la lección cervantina de lectura inversa. Su juego irónico implica "escuchar" al otro y "ensayar" posibilidades de vida.

\section{REFERENCIAS BIBLIOGRÁFICAS}

AZORÍN (1963): Obras completas, vol. IX, Madrid, Aguilar.

BLOOM, Harold (2005): "Don Quijote después de cuatro siglos", en El país de Don Quijote, VV.AA. Madrid, Punto de lectura, 89-98.

CARO VALVERDE, M $\mathrm{M}^{\mathrm{a}}$ Teresa (2009): Quijote Mundo: la baraja de las competencias comunicativas, Murcia, Consejería de Educación, Formación y Empleo.

CEJADOR, Julio (1905): La lengua de Cervantes. Gramática y diccionario de la lengua castellana en "El ingenioso hidalgo Don Quijote de la Mancha", T. 1, Madrid, Jaime Ratés.

CERVANTES, Miguel de (2001): Don Quijote de la Mancha, Barcelona, Crítica. CLOSE, Anthony (2005): La concepción romántica del Quijote, Barcelona, Crítica. FOX, E. I. (1997): La invención de España, Madrid, Cátedra. 
FUENTES, Carlos (2005): "Elogio de la incertidumbre", en El pais de Don Quijote, VV.AA., Madrid, Punto de lectura, 156-171.

GARCÍA MONTERO, Luis (ed.) (2005): La poesía, señor hidalgo... (Antología de poemas cervantinos), Barcelona, FNAC.

GONZÁLEZ GARCÍA, María (2009): Educar con el Quijote: del canon al hipertexto, Editum, Murcia.

GUERRERO RUIZ, Pedro (2006): "El Quijote, pedagogía de una disidencia (Investigación de Educación Literaria)", en Multiárea. Revista de Didáctica, 1, 27-44.

HERRERO, Ángel (1998): Semiótica y creatividad (La lógica abductiva), Madrid, Palas Atenea.

LÁZARO CARRETER, Fernando (1985): "La prosa del Quijote", Lecciones cervantinas, En A. Egido (ed.), Zaragoza, CAZAR, 113-129.

MENDOZA FILLOLA, Antonio (2001): El intertexto lector, Cuenca, Ediciones de la Universidad de Castilla-La Mancha.

(2004): La educación literaria. Bases para la formación de la comptencia lectoliteraria, Málaga, Ediciones Aljibe.

ORTEGA Y GASSET, José (1987): Epistolario completo. Ortega-Unamuno, Madrid, Revista de Occidente.

PEIRCE, Charles Sanders (1980): Semiotica, Torino, Einaudi. Selección y compilación de M. A. Bonfantini.

POZUELO YVANCOS, José M $\mathrm{M}^{\mathrm{a}}$ y ARADRA SÁNCHEZ, Rosa Ma (2000): Teoría del canon y literatura española, Madrid, Cátedra.

POZUELO YVANCOS, José $\mathrm{M}^{\mathrm{a}}$. (2005): "Invitación al Quijote: una novela para leer", en Campus. Revista Cultural de la Universidad de Murcia. $5^{\mathrm{a}}$ época, 4, 4-5.

RILEY, E. C. (1981): Teoría de la novela en Cervantes, Madrid, Taurus.

RODARI, Gianni (1991): Gramática de la fantasía, Barcelona, Aliorna.

RODRÍGUEZ, Juan Carlos (2003): El escritor que compró su propio libro. Para leer el Quijote, Barcelona, Debate.

STEINER, Georges (1998): Errata. Examen de una vida, Madrid, Siruela.

TALENS, Jenaro (1994): "El lugar de la Teoría de la Literatura en el lenguaje electrónico", en Curso de Teoría de la Literatura, D. Villanueva (coord.), Madrid, Taurus, 129-143.

TODOROV, Tzvetan (2009): La literatura en peligro, Barcelona, Círculo de lectores / Galaxia Gutenberg.

TORRENTE BALLESTER, Gonzalo (1975): El Quijote como juego, Madrid, Guadarrama.

VIGOTSKY, Lev Semenovich (1982): La imaginación y el arte en la infancia, Madrid, Akal. 